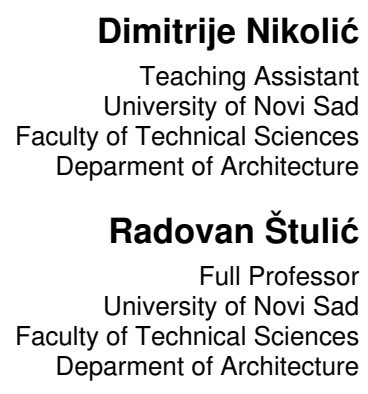
Faculty of Technical Sciences

Radovan Štulić

University of Novi Sad

Deparment of Architecture

\section{Equilibrium Analysis of Frictionless Triangular Arches: Geometrical Formulation}

At the beginning of the scientific research on vaulted structures, during the eighteenth century, scholars such as De la Hire, Couplet and Coulomb, primarily considered an arch made of voussoirs with the joints that have neither friction nor cohesion between them. Accordingly, in order to ensure the equilibrium of the voussoirs, for given extrados and intrados, the problem of determining the direction of the joints was imposed, since the resultant thrust forces must be perpendicular to them. This paper derives and elaborates in detail the explicit equation that defines the precise position and orientation of the joints in a triangular arch of general shape. For the two commonly used shapes, namely flat arch or plate-bande and triangular arch with its intrados and extrados both perpendicular to springings, the closed-form expression of thrust line is obtained. In addition, the paper provides the minimum thickness for various springing angles.

Keywords: Frictionless, Thrust line, Statical approach, Triangular arch, Plate-bande, Minimum thickness.

\section{INTRODUCTION}

Ancient builders have invented different types of structural elements in order to cover openings in a wall or to span space between columns. In the first place, there was lintel, a piece of monolithic block used in trabeated structural system, and later different types of so called false or corbel arches were introduced. Inclined blocks forming triangular headed opening were commonly present in Anglo-Saxon style [1]. The invention of arch had provided greater opportunity; however, their construction had been based solely on experience and intuition [2] until the beginning of the scientific research during the eighteenth century. Scholars such as De la Hire [3] and Couplet [4] among others, primarily considered an arch as the series of rigid blocks or voussoirs with the joints (beds) that have neither friction nor cohesion between them. Accordingly, the resultant thrust forces must be normal to the joints and the fact is expressed by the following fundamental equality:

$$
\frac{V(\psi)}{H}=\tan \psi
$$

whereas the $V$ and $H$ are the vertical and horizontal component of the resultant force, and the $\psi$ is the angle between the direction of the joint and the vertical.

Thereafter, Coulomb [5] posed a problem of determining the direction of the joints for given extrados and intrados, so that voussoirs are in equilibrium [6]. Researchers usually took general

Received: June 2016, Accepted: November 2016

Correspondence to: Dimitrije Nikolić

Faculty of Technical Sciences,

Trg Dositeja Obradovića 6, 21000 Novi Sad, Serbia

E-mail: dima@uns.ac.rs

doi:10.5937/fmet1702307N

(C) Faculty of Mechanical Engineering, Belgrade. All rights reserved consideration, and showed the application to the case of a flat arch i.e. plate-bande [7], and they have concluded that all the joints have to be concurrent to a single point [4, 5, 8, 9]. Using geometrical formulation i.e. static approach, Aita [10] has carried out the specific generalisation of this problem to the triangular shape of an arch, and has provided implicit equation for the direction of joints. Treatises on stereotomy dealt with the design of vaulted structures, concerning the inclination of the joints between voussoirs, within essentially geometrical terms without taking any statical consequences into account [11]. Coulomb's condition that resultant forces must be contained within the masonry imposed a limit to the thickness of a platebande; this was later inspected by Mascheroni who derived the expression which correlates the thickness, span and the springing angle [8]. However, for the detection of minimum thickness, when the geometry of an arch is slightly more complex, more detailed analysis of internal forces is necessary. Hence, the concept of thrust line, being the locus of the application points of the resultant thrust forces at the joints between the voussoirs of the arch, has been introduced, enabling the graphical interpretation of the load path $[12,13]$. More than a century ago, Milankovitch [14] provided the exact solution for the minimum thickness of the semicircular arch and recently Alexakis and Makris [15] have computed the minimum thickness of elliptical arches. Although triangular arches are the structural precedent of the mentioned ones, their structural behaviour is not sufficiently researched.

The aim of this paper is to ameliorate and extend the geometric approach used in [10], through the detailed derivation of the explicit equation that defines the precise both position and direction of the joints between voussoirs of an triangular arch of general shape. Subsequently, the expression of thrust line is derived 
and the minimum thickness for the commonly used shapes are computed. In Sec. 2.1 the particular geometric elements, necessary for the analytical modelling of frictionless triangular arch of general shape, are identified and in Secs. 2.2, 2.3 and 2.4 the analysis is applied to particular shapes, reducing the general expressions. On this basis, the closed form expressions of the thrust line of triangular arches are derived in Sec. 3. The minimum thickness of two particular cases, is considered in Sec. 4; thus, equilibrium analysis is conducted for various embrace angles, and numerical solutions are computed.

\section{ANALYTICAL MODELLING OF JOINTS' DIREC- TION}

\subsection{Triangular arch of general shape}

Consider now the triangular arch which has straight intrados and extrados of different inclination, with the arbitrarily inclined springing, as shown in Fig. 1 (a). Due to the symmetry of the arch, in the following discussion only half-arch is considered.

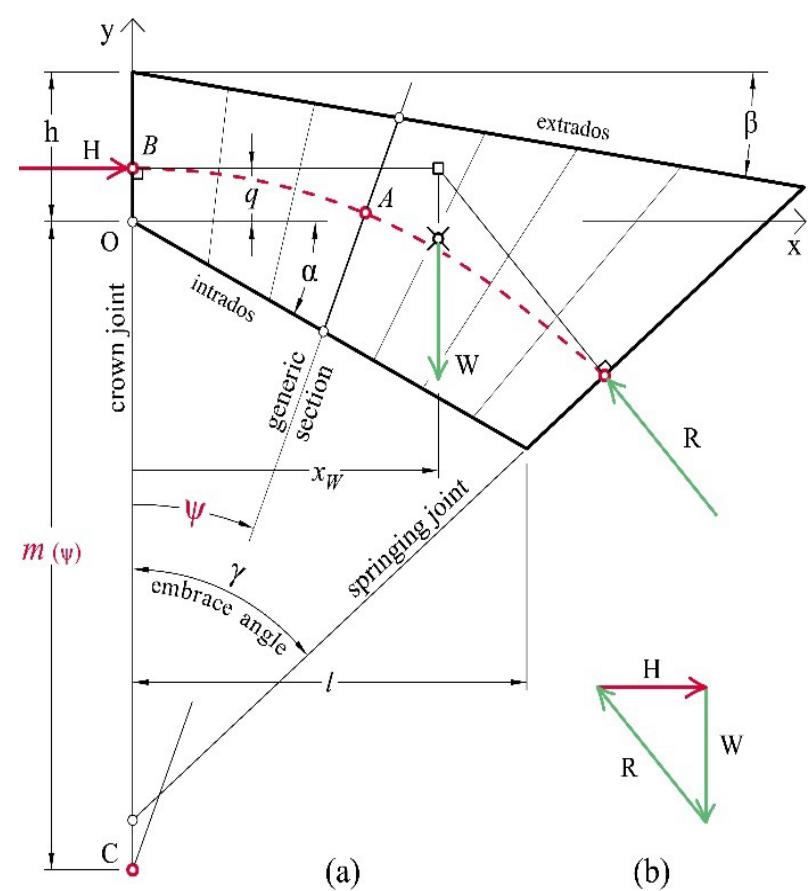

Figure 1. Geometric parameters of triangular arch of general shape

The value $h$ is the height of the arch at the crown, and the length $l$ represents the half-span of the triangular arch. Angles $\alpha$ and $\beta$ represent the inclination of intrados and extrados, respectively, and the embrace angle $\gamma$ is the angle between the springing joint and the vertical crown joint. The angle $\psi$ is angular coordinate, which defines the generic section, and is measured from the axis of the symmetry of the arch. Its local origin, denoted by $C$, moves along the vertical axis, and the distance from the fixed point $O$ is represented by the value $m(\psi)$ which is of particular interest in this paper.

Since the arch is indeterminate to the third degree, there is a family of possible equilibrium solutions, which can be visualized with lines of thrust (traced with the dashed line) obtained through graphical statics methods [16]. In order to obtain statical determinacy of the arch, one point a thrust line passes through has to be assumed; the point $B$, being the application point of the horizontal thrust $H$ acting at the crown joint is chosen, and its position is defined by the value $q$, being the vertical distance from the point $O$. According to (1), the reaction force $R$ acts perpendicularly to the springing joint. Furthermore, in order to satisfy equilibrium, its line of action passes through the intersecting point between horizontal line set through the point $B$ and vertical line set through the centre of gravity of the halfarch at the distance $x_{\mathrm{W}}$, as one can see in Fig. 1 (a).

The problem of the stability of an arch is reduced to mainly geometrical tasks solving. Namely, along with the usual adoption of unit value for specific weight of the material and the depth of an arch, a self-weight of the arch or its portion is substituted by the area of the corresponding arch segment, limited by extrados and intrados lines and by the particular joints between voussoirs; then it is applied in the centre of gravity i.e. in the centroid of the limited area.

From the following equality: $r \cos \psi=-\mathrm{r}(\psi) \tan \beta+\mathrm{h}$ $+m(\psi)$, which represents the abscissa of the intersecting point between polar axis i.e. generic section at the angle $\psi$ and the extrados (expressed in polar coordinates), we solve the radial distance between the point $C$ and the extrados, given by the following expression:

$$
r_{e}(\psi)=\frac{h+m(\psi)}{\tan \alpha \sin \psi+\cos \psi}
$$

Analogously, from $\operatorname{rcos} \psi=\mathrm{m}(\psi)-\mathrm{r}(\psi) \tan \alpha \sin \psi$ we solve the radial distance between the point $\mathrm{C}$ and the intrados, given by:

$$
r_{1}(\psi)=\frac{m(\psi)}{\tan \alpha \sin \psi+\cos \psi}
$$

The weight $V$ of the upper portion of the arch, between crown joint and a generic section at the angle $\psi$, is represented by the corresponding area of the arch (Fig. 3 (a)), and can be computed as the difference between the areas of two triangles, according to the following expression:

$$
\begin{aligned}
& V(\psi)=\int_{0}^{\psi} \frac{1}{2}\left(r_{e}^{2}(\varphi)-r_{i}^{2}(\varphi)\right) d \varphi \\
& \operatorname{in} \psi\left\{\begin{array}{c}
\cos \alpha\left[\begin{array}{c}
h \cos \beta(h+2 m(\psi)) \cos \psi \\
m^{2}(\psi) \sin \beta \sin \psi
\end{array}\right]+ \\
\sin \alpha \cos \beta(h+m(\psi))^{2} \sin \psi
\end{array}\right] \\
& =\frac{2 \cos (\alpha-\psi) \cos (\beta-\psi)}{\text { for } m(\psi)=\text { const. }, \varphi \in[0, \psi]}
\end{aligned}
$$

Abscissa $x_{\mathrm{V}}$ of the centre of gravity of the upper portion of the arch, i.e. of the centroid of the area which corresponds to the weight $V$, is derived as shown in (5).

The weight $W$ of the half-arch and the abscissa $x_{\mathrm{W}}$ of its centre of gravity can be obtained from (4) and (5), when the value of the generic angle $\psi$ reaches the value of the embrace angle $\gamma$. 


$$
\begin{aligned}
& x_{V}(\psi)=\frac{1}{3 V(\psi)} \int_{0}^{\psi}\left(r_{e}^{3}(\varphi)-r_{i}^{3}(\varphi)\right) \sin \varphi d \varphi \\
& =\left.\frac{1}{2}\left[\begin{array}{c}
\frac{\cos ^{4} \beta(h+m(\varphi))^{3}}{\cos ^{2}(\beta-\varphi)}+ \\
\frac{2 \sin \beta \cos ^{2} \beta(h+m(\varphi))^{3} \sin \varphi}{\cos (\beta-\varphi)}- \\
\frac{2 m^{3}(\varphi) \sin \alpha \cos ^{2} \alpha \sin \varphi}{\cos (\beta-\alpha)}- \\
\frac{m^{3}(\varphi) \cos ^{4} \alpha}{\cos ^{2}(\alpha-\varphi)}
\end{array}\right]\right|_{0} ^{\frac{1}{3 V(\psi)}} \\
& =\frac{\left\{\sin \psi \cos (\alpha-\psi)\left[\cos ^{2} \beta(h+m(\psi))^{3}-\frac{m^{3}(\psi) \cos ^{2} \alpha \cos ^{2}(\beta-\psi)}{\cos ^{2}(\alpha-\psi)}\right]\right\}}{\cos (\beta-\psi)\left\{\begin{array}{c}
3 \sin \alpha \cos \beta(h+m(\psi))^{2} \\
\left.3 \cos \alpha\left[\begin{array}{c}
h \cos \beta(h+2 m(\psi)) \cos \psi- \\
m^{2}(\psi) \sin \beta \sin \psi
\end{array}\right]\right\}
\end{array}\right\}}
\end{aligned}
$$

Substituting (4) into the fundamental equality given by (1), the distance $m$ can be solved explicitly as follows:

$m(\psi)=\frac{\left[\begin{array}{c}h \cos \beta(\cos \alpha \cot \psi+\sin \alpha)- \\ \cos \psi \sqrt{\cos (\alpha-y) \cos (\beta-\psi)\left(\begin{array}{c}h^{2} \cos \alpha \cos \beta \\ 2 H \tan \psi \sin (\alpha-\beta)\end{array}\right)}\end{array}\right]}{-\sin (\alpha-\beta)}$

The unknown value of the horizontal thrust $H$ can be solved from (6) using the boundary condition which defines that the direction of springing joint (when $\psi=\gamma$ ) which meets the arch's axis of symmetry at the distance $m(\psi=\gamma)=l \tan \alpha+l \cot \gamma$ from the point $O$, so that the value $H$ is:

$$
H=\frac{1}{2} \frac{\cos \gamma}{\cos (\beta-\gamma)}\left\{\begin{array}{c}
\cos \beta\left[\begin{array}{c}
l(\tan \alpha+\cot \gamma) \\
(l \tan \alpha+2 h)+h^{2}
\end{array}\right]- \\
l^{2} \sin \beta(\tan \alpha+\cot \gamma)
\end{array}\right\}
$$

Combining with (7), (6) becomes:

$$
m(\psi)=\frac{\left\{\begin{array}{c}
h \cos (\cos \alpha \cot \psi+\sin \alpha)- \\
\cos (\alpha-\psi) \cos (\beta-\psi) \\
h^{2} \cos \alpha \cos \beta+ \\
\cos \gamma \tan \psi \frac{\sin (\beta-\gamma)}{\cos (\beta-\gamma)} \\
{\left[\begin{array}{c}
l(\tan \alpha+\cot \gamma) \\
(l \tan \alpha+2 h)+h^{2}
\end{array}\right]} \\
\cos \beta\left[\begin{array}{c}
2 \\
l^{2} \sin \beta(\tan \alpha+\cot \gamma)
\end{array}\right\}
\end{array}\right\}}{-\sin (\alpha-\beta)}
$$

Thus, the distance $m$ of the intersecting point $C$ between a joint's direction and the vertical axis of symmetry from the intrados of the arch (point $O$ ) is obtained as the function of the generic angle $\psi$. Accordingly, for the chosen inclination i.e. the direction of a joint between two voussoirs, its specific position can be determined using (8). This also applies in the particular case where extrados is horizontal (and intrados remains inclined), i.e. when $\beta=0$, as shown in Fig. 2 (a); other particular cases regarding parallel intrados and extrados are considered in the following sections.

\subsection{Triangular arch with equally inclined intrados and extrados}

When the intrados and extrados are parallel i.e. equally inclined, the thickness of triangular arch becomes constant, as shown in Fig. 2 (b). Hence, the angle $\beta$ becomes equal to the angle $\alpha$, so that expression for the weight of arch portion, given by (4), reduces to:

$$
V(\psi)=\frac{1}{2} h \cos \alpha(h+2 m(\psi)) \sin \psi \sec (\alpha-\psi)
$$

and (5) becomes:

$$
x_{V}(\psi)=\frac{\cos \alpha\left(h^{2}+3 h m(\psi)+3 m(\psi)^{2}\right) \sin \psi}{3(h+2 m(\psi)) \cos (\alpha-\psi)}
$$

Further, substituting (9) into (1) one can solve the value $m$ :

$$
m(\psi)=\frac{H \tan \alpha \tan \psi}{3(h+2 m(\psi))}+\frac{H}{h}-\frac{h}{2}
$$

Now the value $H$ is as follows:

$$
H=\frac{1}{2} h \cot \gamma\left(\frac{h}{\tan \alpha+\cot \gamma}+2 l\right)
$$

and thus (11) becomes:

$$
m(\psi)=\frac{\tan \alpha \tan (\psi+1)(2 l \tan \alpha+2 l \cot \gamma+h)}{2(\tan \alpha+\cot \gamma) \tan \gamma}-\frac{h}{2}
$$

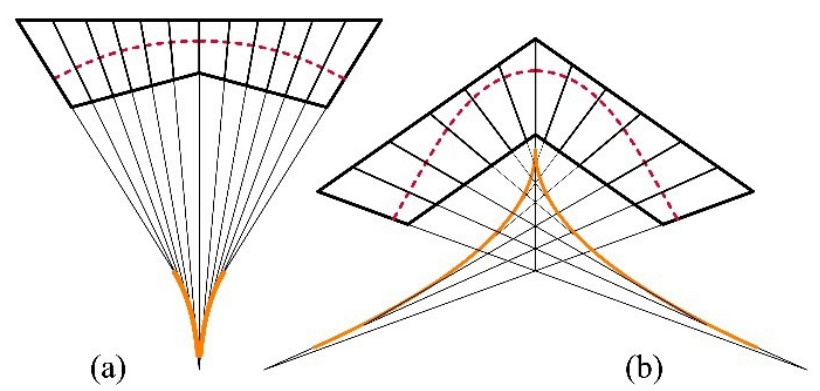

Figure 2. Particular shapes of triangular arch: (a) inclined intrados with horizontal extrados, (b) equally inclined intrados and extrados

\subsection{Intrados and extrados with perpendicular springing}

For more specific and most common case, when springing joint is perpendicular to intrados and extrados, i.e. when $\gamma=\alpha$, the weight $V$ of the arch portion simplifies from (9) to:

$$
V(\psi)=\frac{1}{4} h \cot \alpha \tan \psi(h \sin (2 \alpha)+4 l)
$$


and the abscissa $x_{\mathrm{V}}$ of its centre of gravity is obtained by the substitution of $m(\psi)$ given by (16) into (10). Now, the horizontal thrust $H$ is:

$$
H=\frac{1}{2} h \cot \alpha\left(\frac{h}{\tan \alpha+\cot \alpha}+2 l\right)
$$

In addition, the distance $m$ simplifies from (13) to:

$$
m(\psi)=\frac{1}{2}\left[\begin{array}{c}
h \cos \alpha(\sin \alpha \tan \psi+\cos \alpha)+ \\
2 l(\cot \alpha+\tan \psi)-h
\end{array}\right]
$$

\subsection{Plate-bande}

The most particular case, but also the most common one, represents flat arch or plate-bande. Herewith, both intrados and extrados are horizontal, i.e. $\alpha=\beta=0$. Therefore, the expressions given by (9), (10) and (12) are reduced to (17) - (19), respectively:

$$
\begin{aligned}
& V(\psi)=\frac{1}{2} h \tan \psi(2 l \cot \gamma+h) \\
& x_{V}(\psi)=\frac{\tan \psi\left(3 h l \cot \gamma+3 l^{2} \cot ^{2} \gamma+h^{2}\right)}{3(2 l \cot \gamma+h)}
\end{aligned}
$$

and

$$
H=\frac{1}{2} h(2 l \cot \gamma+h)
$$

Furthermore, (13) reduces to the following equality:

$$
m=l \cot \gamma
$$

One can see that this distance is common for any generic section, since it is independent of the angle $\psi$. Therefore, all the joints are concurrent, i.e. they converge to a single point, the result already obtained by the eighteenth century scholars (e.g. [4, 5] among others), but here it is provided for the completeness of the analysis.

\section{THRUST LINE ANALYSIS OF TRIANGULAR ARCHES}

In order to obtain the graphical representation and the better understanding of the flow of forces along the arch, thrust line analysis is conducted in this section. Consider the finite portion of a triangular arch of general shape (discussed in Sec. 2.1) shown in Fig. 3.

We assume the position of the application points $B$ of the horizontal thrust $H$ acting at the crown, defined by the value $q$. Now, the resultant thrust force $T$ at the generic section at the angle $\psi$ together with its point of application $A$ is uniquely determined from the force and moment equilibrium of the finite portion of the arch; it can be done either graphically with the force polygon (see Fig. 1 and 3) or analytically by solving equilibrium equations.

From rotational equilibrium about point $A$ it follows: $H(m(\psi)-\rho(\psi) \cos \psi+q)=V(\psi) \rho \sin \psi-x_{V}(\psi)$

Hence, from the previous equality, one can determine the distance $\rho(\psi)$ between the thrust line and the point $C$, deriving the closed form expression for the thrust line of triangular arch of general shape:

$$
\rho(\psi)=\frac{H(m(\psi)+q)+V(\psi) x_{V}(\psi)}{H \cos \psi+V(\psi) \sin \psi}
$$

whereas $V(\psi), x_{\mathrm{V}}(\psi), H$ and $m(\psi)$ and are given by (4), (5), (7) and (8), respectively; substituting these expressions into (21) one can obtain the expanded expression of the thrust line (not reported here because of its length).

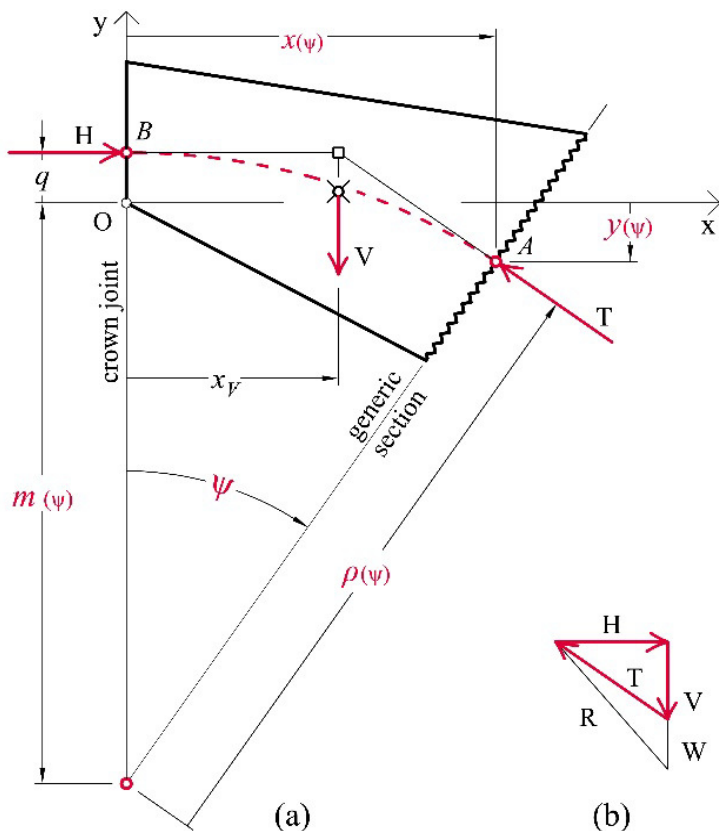

Figure 3. Thrust line: (a) free-body diagram of the isolated finite i.e. top portion of triangular arch up to the generic section at the angle $\psi$, (b) force polygon which represents the equilibrium of the finite portion of the arch

In the particular case, where intrados and extrados are parallel and perpendicular to the springing (Fig. 4 (a) and (b)), (14)-(16) with respect to (10) have to be substituted into (21) in order to obtain the corresponding expression of the thrust line.

In the case of plate-bande, the expression of the thrust line simplifies to the following one:

$$
\rho(\psi)=\frac{\cos \psi\left[\begin{array}{c}
3 l \cot \gamma \sec ^{2} \psi(h+q \cos (2 \psi)+q)+ \\
3 l^{2} \cot ^{2} \gamma\left(\tan ^{2} \psi+2\right)+ \\
3(2 l \cos \gamma+3 q)
\end{array}\right]}{3(2 l \cos \gamma+h)}
$$

Plotting the graph of thrust line, as well as the analysis of its position, in order to detect minimum thickness, requires the parametrisation of (21) in the following form:

$$
\begin{aligned}
& x(\psi)=\rho(\psi) \sin \psi \\
& y(\psi)=\rho(\psi) \cos \psi-m(\psi)
\end{aligned}
$$

where the origin of orthogonal coordinate system is positioned in the point $O$, as shown in Fig. 3 (a). 
A few scholars have concluded that in general case the direction of the resultant thrust force does not coincide with the direction of the tangent line to thrust line (see for example $[13,14,17,18]$ ), i.e. $V / H \neq \mathrm{d} x / \mathrm{d} y$. Slope of the resultant developed at the generic joint at the angle $\psi$ can be determined as the ratio between the derivatives of the expressions given in (23):

$$
\frac{d x}{d y}=\frac{\frac{d x}{d \psi}}{\frac{d y}{d \psi}}
$$

Numerical analysis has shown that (24) equals zero when $\psi=0$, and when $\psi=\gamma$ it is different from $-\tan \gamma$. In other words, thrust line is perpendicular to the crown joint and is not perpendicular to the springing joint.

\section{MINIMUM THICKNESS}

Expressions for the thrust line given in the previous section do not assume a limit thrust line i.e. the minimum (limit) thickness of the arch with the corresponding limit value of horizontal thrust. In order to determine the limit thrust line, it is necessary to determine the admissible collapse mode i.e. limit equilibrium state (see Fig. 4).

\section{a. Minimum thickness of frictionless perpendicular triangular arch}

When the triangular arch with parallel extrados and intrados is considered, the application point of the horizontal thrust at the crown joint has to be set at its lower extremity, so that point $B$ coincides with the point $O$ and the value $q$ equals zero. From that point thrust line departures from intrados approaching extrados. Numerical analysis with respect to (24) has shown that when $\psi=\gamma$ the slope of thrust line is smaller than the slope of the extrados. Therefore, when the limit state is assumed, thrust line firstly touches extrados close to springing, and then it approaches the springing moving away from the extrados; at the springing joint, it passes between extrados and intrados, but much closer to the extrados, as shown in Fig. 4 (b).

Triangular arch of sufficient thickness $t=h \cos \alpha$ is shown in Fig. 4 (a) and one admissible thrust line is traced according to (23). We search for the (minimum) thickness necessary to accommodate only one, i.e. limit thrust line. In other words, it is necessary to detect the point of the thrust line with the tangent coincident to the extrados. The analytical solution is not known to the authors, so the numerical solutions have been obtained through the developed iterative process. Namely, for each generic section, the distance along the polar axis between the thrust line, i.e. the application point of the resultant thrust force, and the extrados is computed, and the minimal value which defines critical section is detected. In order to obtain the limit thickness of the arch, it has to be modified in iterative procedure regarding the critical section, until the thrust line reaches the extrados up to a satisfactory precision; in the conducted calculations, all the values have been computed with the precision of $10^{-14}$. Thus, the numerical values of the theoretical minimum thicknesses for the most common inclination angles are provided in Tab. 1.

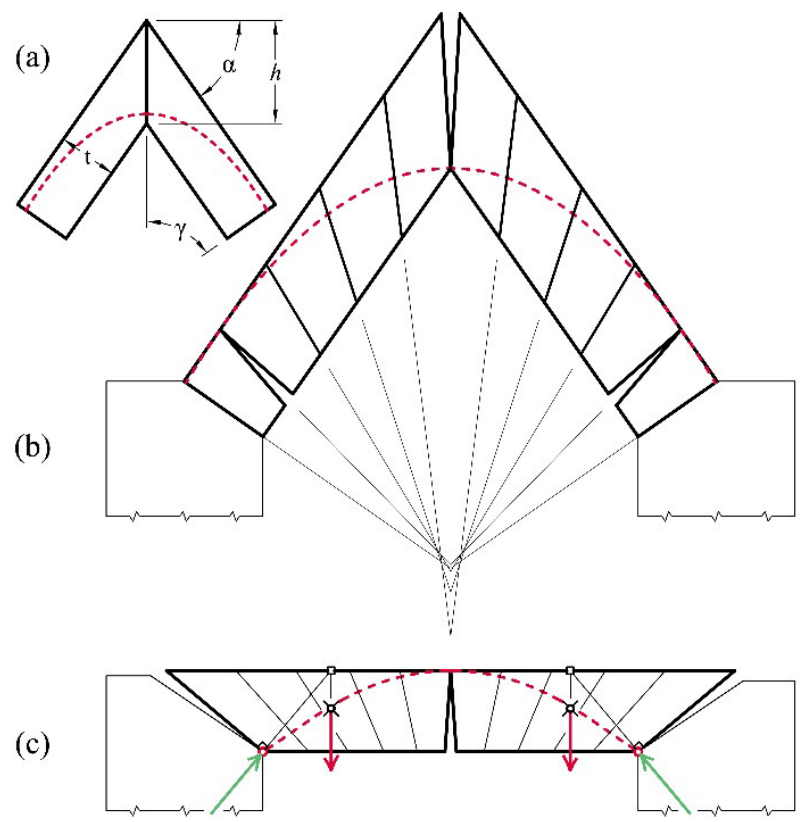

Figure 4. (a) Arch of sufficient thickness; limit equilibrium state and the corresponding minimum thickness: (b) perpendicular triangular arch, (c) plate-bande

Table 1. Minimum thickness $t / l$ of triangular arch of equally inclined intrados and extrados with perpendicular springing

\begin{tabular}{|c|c|c|c|c|}
\hline$\alpha\left[^{\circ}\right]$ & 15 & 30 & 45 & 60 \\
\hline$t / l$ & 0.131662 & 0.268033 & 0.412902 & 0.563537 \\
\hline
\end{tabular}

On the basis of numerical results obtained for embrace angles from 2,5 to 62,5 stepwise 2,5 degrees, the correlation between inclination angle and the minimum thickness can be approximated with satisfactory accuracy by the following expression:

$$
t / l=0.000015 \alpha^{2}+0.00847 \alpha+0.00086
$$

One can see that this correlation is approximately linear, since the quadratic coefficient in (25) is almost three magnitudes lower than the linear one. It has also been concluded that for the greater value of embrace angle different analytical modelling has to be formulated, since the value $m$ reaches negative value for the arch portion around the crown.

\section{b Minimum thickness of frictionless plate-bande}

In order to satisfy equilibrium of plate-bande, lines of action of horizontal thrust acting at the crown, reaction force acting perpendicularly to the springing and the weight of the half plate-bande acting vertically at its centre of gravity have to be concurrent [5]. When the minimum thickness is assumed, the application point of the horizontal thrust at the crown has to be set at its higher extremity, so that the value $q=h$, and the reaction force acts at the springing's lower extremity (Fig. 4 (c)), and this is expressed by the following equality: 


$$
h=\left(l-x_{W}\right) \tan \gamma
$$

where the abscissa $x_{\mathrm{W}}$ of the centre of gravity of half plate-bane is obtained when $\psi=\gamma$ according to (18), so it becomes:

$$
x_{W}=\frac{h(h \tan \gamma+3 i)+3 l^{2} \cot \gamma}{3(2 i \cot \gamma+h)}
$$

Now, from (26) we solve $h$ and divide by $l$, obtaining the explicit solution for the minimum thickness as the function of embrace angle:

$$
t / l=\frac{\sqrt{3 \sec ^{4} \gamma+3 \sec ^{2} \gamma+3}-3}{\tan ^{3} \gamma+3 \tan \gamma}
$$

Numerical solutions of (28) for the various embrace angles $\gamma$ which correspond to the common springing angles are given in Tab. 2 .

Table 2. Minimum thickness $t / l$ of plate-bande for the different values of embrace angle $y$

\begin{tabular}{cccccc}
\hline$\gamma\left[^{\circ}\right]$ & 15 & 30 & 45 & 60 & 75 \\
\hline$t / l$ & 0.131599 & 0.265983 & 0.395644 & 0.475087 & 0.376158 \\
\hline
\end{tabular}

It should be noted that the value which corresponds to $30^{\circ}$ is in accordance with the one obtained by Venturoli [8]. In addition, it is derived that the maximum of (28), representing the maximum value of minimum thickness, corresponds to $\gamma=61,57^{\circ}$. In the frame of Couplet's assumptions on structural behaviour of material, flat arches are infinitely strong regardless thickness [19]; however, within the frictionless hypothesis, as we can see, finite thickness is required to ensure stability. Substituting (28) into (19) we derive the value of horizontal thrust for the plate-bande of minimum thickness:

$$
H_{\min }(\gamma)=\frac{l^{2}\left(3 \sec ^{2} \gamma+2 \sqrt{3\left(\sec ^{4} \gamma+\sec ^{2} \gamma+1\right)}\right)}{2 \tan ^{4} \gamma\left(3 \cot ^{2} \gamma+1\right)^{2}}
$$

Inspecting (30), for the unit value of half-span $l$, one can conclude that horizontal thrust decreases very little up to $45^{\circ}$, and that after $60^{\circ}$ it decreases very rapidly. Furthermore, one can conclude that the flat arch which has the usually used embrace angle of $30^{\circ}$ (springing angle equals $60^{\circ}$ ) has low minimum thickness value, but oppositely exerts great horizontal thrust.

\section{CONCLUSION}

Frictionless hypothesis has been considered from the beginning of the scientific research on vaulted structures, and remains of particular interest to present days. One of the main tasks is the determination of appropriate stereotomy, i.e. the way of cutting the particular voussoirs that form an arch, in order to ensure only normal component of the resultant thrust forces at the joints between the voussoirs.

This paper examined equilibrium solutions of the triangular arch of general shape in the absence of friction and cohesion. Thus, the explicit equation for the direction of joints between voussoirs has been derived. Further, the thrust line analysis under frictionless hypothesis has been conducted and the closed-form expression for the thrust line has been obtained. Two common shapes, namely flat arch or plate-bande and triangular arch which has intrados and extrados perpendicular to springing have been treated in detail. Hence, the limit equilibrium states have been considered, and the numerical solutions for minimum thickness regarding common values of springing angle have been computed.

The analysis carried out in this paper may be used as the basis for statical formulation for the case of circular arch. The correlation between arch's shape and the envelope of the directions of joints between voussoirs, may be analysed. In order to obtain results closer to practical structural behaviour, it is necessary to conduct an analysis within the framework of limit equilibrium analysis, which concerns friction, what is the subject of further research.

\section{ACKNOWLEDGMENT}

The paper was done within the Project No. TR36042 supported by the Ministry of Education, Science and Technological Development of the Republic of Serbia.

\section{REFERENCES}

[1] Bloxam, M. H.: The principles of Gothic ecclesiastical architecture, Vol. 1, George Bell and sons, London, 1882.

[2] Benvenuto, E.: 1991. An introduction to the history of structural mechanics, Springer-Verlag, New York, 1991.

[3] De la Hire, P.: Traité de mécanique. Imprimerie Royale, Paris, 1695.

[4] Couplet, P.: De la poussée des voûtes. Histoire de l'Académie Royale des Sciences, pp. 79-117 and pp. 117-141, 1729, 1730.

[5] Coulomb, C. A.: Essai sur une application des règles de Maximis \& Minimis à quelques Problèmes de Statique, relatifs à l'Architecture, Mémoires de mathématique et de physique, Présentés à l'Académie Royale des Sciences par divers Savans, vol. 7, pp. 343-382, 1776.

[6] Heyman, J.: Coulomb's memoir on statics: An essay in the history of civil engineering, Cambridge university press, 1972.

[7] Huerta, S.: Wedges and plate-bandes: mechanical theories after De la Hire, in: Gargiani R. (Ed.): L'architrave, le plancher, la plate-forme. Nouvelle Histoire de la construction. Architecture Essais. Presses polytechniques et universitaires romandes, Lausanne, pp. 405-435, 2012.

[8] Mascheroni, L.: Nuove ricerche sull' equilibrio delle volte, Francesco Locatelli, Bergamo, 1785.

[9] Venturoli, G.: Elements of Practical Mechanics (English translation, original: Elementi di Meccanica, 1806), Cambridge and London, 1823.

[10] Aita, D.: Una possibile rilettura del problema dell'arco tra geometria e meccanica. in: $15^{\text {th }}$ AIMETA Congress of Theoretical and Applied Mechanics, 2001. 
[11] Aita, D.: Between geometry and mechanics: A reexamination of the principles of stereotomy from a statical point of view, in: Huerta, S. (Ed.): Proceedings of the First International Congress on Construction History. Instituto Juan de Herrera, Madrid, pp. 161-170, 2003.

[12] Young, T.: Bridge. Supplement to the fourth, fifth and sixth editions of the Encyclopaedia Britannica, Vol. 2, Archibald Constable, Edinburgh, pp. $497-$ 520, pl. 42-44, 1824.

[13] Moseley, H.: The Mechanical Principles of Engineering and Architecture, London, 1843.

[14] Milankovitch, M.: Theorie der Druckkurven. Zeitschrift für Mathematik und Physik, Vol. 55, pp. 1-27, 1907.

[15] Alexakis, H., Makris, N.: Minimum thickness of elliptical masonry arches. Acta Mech., Vol. 224, pp. 2977-2991, 2013.

[16] Romano, A., Ochsendorf, J. A.: The mechanics of gothic masonry arches, Int. J. Archit. Herit., Vol. 4, pp. 59-82, 2010.

[17]Foce, F.: Milankovitch's Theorie der Druckkurven: Good mechanics for masonry architecture, Nexus Netw. J., Vol. 9, No. 2, pp. 185-210, 2007.

[18] Alexakis, H., Makris, N.: Limit equilibrium analysis of masonry arches, Arch. Appl. Mech., Vol. 85, No. 9, pp. 1363-1381, 2015.
[19]Heyman, J.: The Stone Skeleton, Cambridge University Press, 1997.

\section{АНАЛИЗА РАВНОТЕЖЕ ИДЕАЛНО \\ ГЛАТКОГ ТРОУГАОНОГ ЛУКА: ГЕОМЕТРИЈСКИ ПРИСТУП}

\section{Д. Николић, Р. Штулић}

С почетка научног приступа у изучавању засвођених структура, током осамнаестог века научници попут Лаира, Куплеа и Кулона су првобитно разматрали лукове добијене ређањем сводних каменова занемарујући трење и кохезију на споју између њих. У складу с тим, резултантне силе морају бити управне на спојеве. Тако се намеће проблем одређивања праваца тих спојева, како би се обезбедила равнотежа лука задатог интрадоса и екстрадоса.

У овом раду се изводи експлицитна једначина тачног положаја и оријентације спојева у троугаоном луку општег облика. Посебно се разматрају раван лук и троугаони лук с интрадосом и екстрадосом управним на ослоначки пресек. На основу тога су добијени изрази за потпорну линију, те су у зависности од угла ослањања израчунате вредности за минималну дебљину. 